\title{
RETROSPECTIVE EVALUATION OF PATIENTS WITH PRIMARY HYPERPARATHYRODISM IN KONYA MERAM FACULTY OF MEDICINE
}

Elif Turan1, Ahmet Kaya1, Bülent Savut1, Gülsüm Gönülalan2, Mustafa Kulaksızoğlu1, 1- Necmettin Erbakan University Meram Faculty of Medicine Department of Endocrinology and Metabolism 2-Konya Numune Hospital, Department of Endocrinology and Metabolism

\section{INTRODUCTION}

Primary Hyperparathyroidism (PHP), is generalized with calcium, phosphate and bone metabolism disorder due to increased PTH secretion. Increase in circulating hormone causes hypercalcemia and hypophosphatemia. It's common in fifth and sixth decades and female-male ratio is 3:1 (1). Nephrocalcinosis, recurrent peptic ulcers, mental changes, and more frequently generalized bone resorption may be observed. Nowadays, with the common measurement of blood calcium, it can be diagnosed with minimal or no symptoms. Cause of hyperparathyroidism is solitary adenoma in $80 \%$ of patients. More rarely parathyroid hyperplasia and parathyroid carcinomas are seen. Parathyroid hyperplasia is familial and usually associated with other endocrine abnormalities (2). In this study, we aimed to evaluate the clinical, radiological, biochemical parameters in patients with primary hyperparathyroidism.

METHOD

102 patients with PHP admitted to department of endocrinology, between years of 2008-2013 were analyzed. Gender, age, serum calcium, phosphorus, PTH, 24 urinary calcium, creatinine clearance, alkaline phosphatase, preoperative ultrasonography, adenoma size were noted. The results of these patients were evaluated retrospectively. Statistical analysis was performed using the programme SPSS for Windows.

\section{RESULTS}

The sample of 102 patients included 80 females and 22 males. Mean age was $54.6 \pm 10.9$. Mean level of serum calcium was 12.03 (9.4-18.4) $\mathrm{mg} / \mathrm{dL}$ ( normal range 8.9-10.3), phosphorus was $2.7 \mathrm{mg} / \mathrm{dL}$ (normal range 2.4-4.7), PTH was $364.5 \mathrm{pg} / \mathrm{mL}(12-88)$, and 24 hours urine calcium was 470 $\mathrm{mg} / 24 \mathrm{~h}$ (100-300). Mean level of alkaline phosphatase was $159 \pm 289 \mathrm{IU} / \mathrm{L}$, creatinine clearance was $94 \pm 36 \mathrm{ml} / \mathrm{min}$. In preoperative ultrasonography, adenoma was detected in 66 of patients. Average adenoma size was $15.76 \mathrm{~mm}$ ( $\mathrm{min}$ size $6 \mathrm{~mm}$ max size $60 \mathrm{~mm}$ ). Fine needle biopsy and parathyroid hormone washing were performed preoperatively in 10 patients for nodule / adenoma differentiation and the average value was $2235 \pm 1488 \mathrm{pg} / \mathrm{mL}$. Parathyroid MIBI scintigraphy was performed in 90 patients and in 70 of them adenomas were detected. Adenomas were most frequently in right inferior localization (52.7\%). The ectopic parathyroid tissue was detected in the mediastinum with MIBI in 1 patient.
In bone densitometry 33 of 60 patients were osteoporotic, 20 were osteopenic and 7 were normal. Bone cysts were detected in 3 patients. History of nephrolithiasis were present in 22 of 99 patients. In total, only 3 of 88 patients had a history of fracture. Minimally invasive surgery (MIS) was performed in 33 patients, open surgery (OS) was performed in 56 patients Postoperative hungry bone syndrome occurred in 25 patients. In pathological evaluation, 71 of 89 patients had parathyroid adenoma, 14 of them had parathyroid hyperplasia, 3 of them had parathyroid carcinoma.

\section{DISCUSSION}

Presentation and clinical manifestations of primary hyperparathyroidism have changed dramatically in recent years. With the widespread use of screening tests like blood calcium, it is diagnosed with often no symptoms or minimal symptoms due to additional disease.

In compliance with the literature, majority of our patients were female and the average age was in the sixth decade. Adenomas were detected in $77 \%$ of patients and were most frequently in right inferior localization $(52.7 \%)$. The incidence of nephrolithiasis in older studies were detected as $70-80 \%$, but it is around $25 \%$ in recent studies (2). In our study, it was $23 \%$.

In recent years, minimally invasive approach is more preferred for the removal of the parathyroid adenomas. Preoperative localization is provided and with the opportunity of outpatient surgery, it may reduce the need of hospitalization. This method should be preferred in patients without the possibility of multi-glandular disease and in case of parathyroid carcinoma area of excision should be expanded (3). The majority of our patients (63\%) were treated with OS, however MIS has lower morbidity than OS in literature. In a study with 37 patients over 70 years, who underwent minimally invasive parathyroid surgery, the mean duration of hospital stay was 2.8 days and also 11 patients were discharged in postoperative 24 hours (4), that is important for morbidity of patients and reducing the cost. Parathyroid ultrasound and sestamibi parathyroid scintigraphy is recommended for preoperative localization. If these two tests indicate the same location it is localized, will be marked. If we cannot define the adenomas with radiologic and scintigraphic methods, fine-needle biopsy and PTH wash can be used. In this way, more patients may have the chance of MIS. REFERENCES

1-Kronenberg HM, Melmed S, Polonsky KS, et al. Hormones and Disorders of Minera Metabolism. In Wiliams Textbook of Endocrinology 11. Edition 2008: 27,1203-1310 2-Tanakol R. Primer Hiperparatiroidi. Türkiye Klinikleri Endokrinoloji. 2011: 4 ;9-19 3-Potts J.T, Paratiroid bezi ve hastalıkları ve diğer hipo ve hiperkalsemik durumlar. Harrison Endokrinoloji. Nobel 2009: 24;431-465

4- Dobrinja C, Silvesti M, Manzini N. Primary Hyperparathyroidism in Older People: Surgical Treatment with Minimally Invasive Approaches and Outcome. International Journal of Endocrinology Volume 2012:1-6 